\title{
Trophic effects of myeloid leukaemia inhibitory factor (LIF) on mouse embryos
}

\author{
T. C. Lavranos ${ }^{1 *}$, P. D. Rathjen ${ }^{2}$ and R. F. Seamark ${ }^{1}$ \\ Department of ${ }^{1}$ Obstetrics and Gynaecology, and ${ }^{2}$ Biochemistry, University of Adelaide, Adelaide, \\ South Australia 5005, Australia
}

\begin{abstract}
Myeloid leukaemia inhibitory factor (LIF) is expressed at highest concentrations in the maternal endometrial glands at about the stage of blastocyst implantation. LIF is also expressed by the extraembryonic membranes of the early mouse embryo. Embryos of different ages were cultured with, or without, LIF, and embryo growth in vivo and in vitro was examined to determine whether LIF is important for embryo development. Supplementing embryo culture media with $1000 \mathrm{U}$ recombinant human LIF $\mathrm{ml}^{-1}$ increased the number of eight-cell mouse embryos developing beyond the hatched blastocyst stage in vitro from $62.1 \%$ to $85.1 \%(P<0.05)$. LIF significantly increased the number of embryos hatching $(33.8 \%$ versus $7.65 \%$ for controls $96 \mathrm{~h}$ after hCG injection, $P<0.001)$, completely hatching $(85.1 \%$ versus $62.1 \%, P<0.05)$, and exhibiting trophoblast outgrowth $(13.5 \%$ versus $0 \% 120 \mathrm{~h}$ after hCG treatment, $85.1 \%$ versus $47.0 \% 144 \mathrm{~h}$ after hCG treatment, $P<0.001)$ in vitro. LIF-treated embryos also displayed a significantly greater area of trophoblast outgrowth than did controls as early as day 5 in culture $(P<0.005)$. These data show that LIF enhances mouse eight-cell embryo development in vitro, as seen by the accelerated rate of embryo hatching and trophoblast outgrowth. In addition, enhanced embryo survival in vivo is shown, following the transfer of LIF-treated embryos into a pseudopregnant recipient female. Expression of mRNA encoding LIF was detected in endometrial cells cultured in monolayer from uteri of day 3 pregnant females, explaining the known embryotrophic effects of endometrial coculture. This expression was not enhanced significantly by treatment with oestradiol $\left(3.7 \times 10^{-5} \mathrm{~mol} \mathrm{l}^{-1}\right)$ or progesterone $\left(3.2 \times 10^{-6} \mathrm{~mol} \mathrm{l}^{-1}\right)$ or both hormones. These results indicate that LIF could have a dual action in early embryogenesis as an embryotrophin and as a factor required for embryo implantation. Multiple roles for LIF are consistent with the expression of this factor at embryonic, extraembryonic and maternal sites during early embryogenesis.
\end{abstract}

\section{Introduction}

The establishment of an appropriate uterine environment during mammalian embryogenesis depends upon complex interactions between embryo and uterus. An increasing body of evidence indicates that peptide-signalling molecules play an important role in this process. These include proteins originally identified as growth factors (see reviews by Hill et al., 1987 and Brigstock et al., 1989) and proteins such as cytokines that were identified in other cellular systems. These molecules are located in the uterus during pregnancy and have been shown to regulate the attachment, implantation, growth and development of embryo and fetus (Pollard et al., 1987; Wegmann, 1988; Arceci et al., 1989; Wegmann et al., 1989; Pollard, 1990; Robertson et al., 1990).

Myeloid leukaemia inhibitory factor (LIF) has pleiotropic activities in a number of mammalian cell systems (Hilton et al.,

*Present address: Department of Medicine, The Flinders University of South Australia, Bedford Park, SA 5042, Australia.

Received 6 March 1995.
1988; Moreau et al., 1988; Smith et al., 1988; Williams et al., 1988; Gough et al., 1989; Metcalf 1989; Yamamori et al., 1989). Several lines of evidence indicate that this protein has important biological activities during early mammalian development (see review by Fry, 1992). LIF is expressed at a variety of sites in both the mother and the early conceptus (Robertson et al., 1993), and has potential biological effects on several cell types in the early embryo. In particular LIF is expressed by the maternal oviduct and uterus, and at high concentrations in the endometrial glands about the stage of implantation (Bhatt $e t$ al., 1991; Shen and Leder, 1992). Embryonic LIF expression has been observed in the extraembryonic membranes of the egg cylinder embryo and continues after gastrulation (Conquet and Brûlet, 1990; Rathjen et al., 1990a). In vitro, LIF can prevent the differentiation of embryonic stem cells (Smith et al., 1988; Williams et al., 1988) which are derived from, and closely related to, cells of the embryonic inner cell mass. Receptors for LIF have also been identified on trophectoderm cells (Fry, 1992). Genetic experiments have indicated that overexpression of LIF in chimaeric embryos can inhibit gastrulation (Conquet 
et al. 1992), while mutation of the LIF gene in female mice prevents embryo implantation (Stewart ef al., 1992). Although the requirement for maternal LIF expression for embryo implantation is well defined, the reasons for the multiple sites of LIF expression during early embryogenesis and potential effects of the cytokine on the embryo at this stage are not clear.

The aim of this study was to explore the possible role of LIF in early embryonic development by analysis of the effects of LIF on embryo development, growth and implantation in vitro.

We have previously shown (Lavranos and Seamark, 1989) that mouse embryo development can also be enhanced by coculture with endometrial cells in the presence of oestradiol and progesterone. To test whether this effect was associated with steroid-induced production of LIF by endometrial cells, these cells were cultured in the presence or absence of steroids and examined for the expression of mRNA encoding LIF by ribonuclease protection assays.

\section{Materials and Methods}

\section{Animals}

Female mice 3-4 weeks-old $\left(\mathrm{F}_{1}: \mathrm{BALB} / \mathrm{c} \times \mathrm{C} 57 \mathrm{Blk}\right.$ strain or $\mathrm{CBA} \times \mathrm{C} 57$ strain as indicated) were given an i.p. injection of 7.5 iu pregnant mares' serum gonadotrophin (Folligon; Intervet Pty Ltd, Sydney) and 7.5 iu hCG (Chorulon; Intervet Pty Ltd) $48 \mathrm{~h}$ later to achieve superovulation. After hCG treatment, each female was placed with a fertile male mouse $(\mathrm{CBA} \times \mathrm{C} 57)$ and left overnight to mate. Each morning after males and females had been caged together, each female mouse was examined for evidence of mating; those with a vaginal plug were considered to be at day 1 of pregnancy, or day 1 of pseudopregnancy. Pseudopregnant female mice, to be used as recipients in embryo transplantation (embryo transfer) experiments, were prepared by mating with vasectomized males $(\mathrm{CBA} \times \mathrm{C} 57)$.

\section{Collection and culture of embryos}

Pregnant females were killed by cervical dislocation either $20 \mathrm{~h}$ after the hCG injection for the collection of one-cell embryos or $71-73 \mathrm{~h}$ after the hCG injection for the collection of eight-cell embryos. The whole reproductive tract was dissected out and placed in equilibrated (with $5 \% \mathrm{CO}_{2}$ in air) Earle's balanced salt solution without calcium or magnesium (EBSS) at $37^{\circ} \mathrm{C}$.

One-cell embryos were recovered from the ampulla of day 1 pregnant $\mathrm{CBA} \times \mathrm{C} 57$ females (4-6 females per replicate), washed twice in culture medium and randomly assigned to either a control or experimental group within $20 \mathrm{~min}$ of collection. All one-cell embryos were cultured in human tubal fluid medium (HTF) which was prepared according to Quinn et al. (1985). Each group consisted of approximately 10-15 embryos placed in a $20 \mu \mathrm{l}$ drop of either (i) HTFunsupplemented medium (control group) or (ii) LIFsupplemented HTF medium, the concentration of LIF varying from $62.5 \mathrm{U} \mathrm{ml}^{-1}$ to $2000 \mathrm{U} \mathrm{ml}^{-1}$. Both control and experimental groups were repeated six times. Embryos were cultured for approximately 5 days in a drop of medium under paraffin oil in an incubator at $37^{\circ} \mathrm{C}$, in a humidified atmosphere of $5 \%$ $\mathrm{CO}_{2}: 5 \% \mathrm{O}_{2}: 90 \% \mathrm{~N}_{2}$. Development of the embryos was assessed as described below.

Eight-cell embryos were teased or flushed out of the oviduct-uterus junction of day 3 pregnant BALB/C $\times$ C57Blk females (4-6 females per replicate), washed twice in culture medium and randomly allocated to either a control group (unsupplemented culture medium) or experimental group (LIFsupplemented culture medium, $1000 \mathrm{U} \mathrm{ml}^{-1}$ ) within $20 \mathrm{~min}$ of collection. The culture medium was prepared as described by Lavranos and Seamark (1989). Briefly, the culture medium was filter-sterilized minimal essential medium (MEM; Eagle, with Earle's salts, with L-glutamine, without sodium bicarbonate; Flow Laboratories, Herts) supplemented with $5.6 \mathrm{mmol}$ glucose $1^{-1}, 25 \mathrm{mmol}$ sodium bicarbonate $1^{-1}, 10 \%(\mathrm{v} / \mathrm{v})$ heatinactivated fetal calf serum, penicillin/streptomycin/fungizone (10 000 units, $10000 \mu \mathrm{g}$ and $25 \mu \mathrm{g}$, respectively, per $100 \mathrm{ml}$ of medium) (CSL, Parkville, Victoria) and the $\mathrm{pH}$ and osmolarity of the medium adjusted to 7.40 and 280 mosmol, respectively. Embryos (10-20) were cultured in $1 \mathrm{ml}$ medium per well (four-well multidish; Nunc, Roskilde), 1-2 wells per replicate, 4-8 replicates per group (according to the experiment). All eight-cell embryos were cultured for 5-7 days in an incubator at $37^{\circ} \mathrm{C}$, in a humidified atmosphere of $5 \% \mathrm{CO}_{2}$ in air, and growth and development were observed, and assessed as described by Lavranos and Seamark (1989). Briefly, the numbers of embryos achieving morula, blastocyst or hatching blastocyst stage as described by Hsu (1979) were recorded daily using an inverted microscope.

\section{Embryo transfers}

The procedure followed for embryo transfers was a modification of the protocol described by Hogan et al. (1986). Once collected, eight-cell embryos were cultured in either unsupplemented medium (controls) or in LIF-supplemented medium (1000 $\mathrm{U} \mathrm{ml}^{-1}$ ) until they reached either the hatchingblastocyst stage or the hatched-blastocyst stage. At each of these stages, four embryos from the control group were transferred to one uterine horn of a day 2.5 pseudopregnant recipient female, and four embryos from the LIF-treated groups were transferred to the contralateral uterine horn of the same animal; 13 females were used for hatching-blastocyst stage embryos and eight females were used for hatched-blastocyst stage embryos. Pseudopregnant females were anaesthetized for the surgical transfer of embryos by i.p. injection of Avertin $(0.14 \mathrm{ml} / 10 \mathrm{~g}$; Winthrop Laboratories, Ermington, NSW). Embryos to be transferred were loaded into a pulled sterile glass pipette and placed to one side until the time of transfer. The pseudopregnant recipient mouse was then placed under a dissecting microscope dorsal surface uppermost and either side of the lower back was plucked free of fur and swabbed with alcohol. A small $(1.5 \mathrm{~cm})$ mid-dorsal incision was made, the ovary located through the body wall and another small incision made avoiding any blood vessels. Part of the reproductive tract was pulled to the outside; the oviduct-uterine junction was located; the pipette containing the embryos was carefully inserted into the uterine lumen and the embryos were expelled. This was carried out for both sides of the reproductive tract. 
Once both sides of the mouse had been used for embryo transfer, the incisions were sutured and the mouse left to recover. The survival rate on the recipient animals following this procedure was $100 \%$ ( 23 of 23 ), with a pregnancy success rate of approximately $90 \%$ ( 21 of 23 ). The recipient mice were allowed to reach day 15 of pregnancy at which time they were killed by cervical dislocation. Uterine horns from each female were assessed for the number of embryos either reabsorbed or the number of live fetuses.

\section{Morphological assessment of embryo development}

All embryos were observed daily, using an inverted microscope, and details of their development recorded during culture for 5-7 days. The numbers of embryos reaching various stages from one-cell for one group of experiments, or eight-cell through to hatching-blastocyst stage (Hsu, 1979) and their rates of development following hCG treatment, were recorded. Further development of these embryos related to implantation was also monitored (Sherman, 1978). On the basis of assessment of morphological development of mouse embryos after the blastocyst stage, as described by Lavranos and Seamark (1989), post-hatching embryos with proliferating trophectoderm cells were recorded as attaining stage 1 , and those with trophectoderm cells attached to the bottom of the dish classed as stage 2. Embryos with trophectoderm cells spread out on the bottom of the dish were classed as stage 3 . The survival rate was calculated as the percentage of embryos that attained stage 3 ; the morphological equivalent in vitro of implantation. Quantitative measurements of stage 3 embryos were made using the Bio-Quant System image analyser and a Leitz microscope.

\section{Expression of LIF in cultures of mixed uterine endometrial cells in the presence or absence of steroids}

The procedure used for the preparation of mixed monolayers from whole uteri previously described by Salomon and Sherman (1975) and following the modifications of Lavranos and Seamark (1989) was as follows: after collection of the embryos from females at day 3 of pregnancy, uteri were dissected free of remaining oviductal and fatty tissue and washed twice in EBSS at $37^{\circ} \mathrm{C}$ under sterile conditions. They were then cut into smaller pieces (approximately $3 \mathrm{~mm}$ long) and placed in a Petri dish containing $0.5 \%(\mathrm{v} / \mathrm{v})$ trypsin and $0.02 \%(\mathrm{v} / \mathrm{v})$ EDTA in EBSS, for $15 \mathrm{~min}$ at $37^{\circ} \mathrm{C}$. The enzyme solution was then replaced with fresh enzyme solution, the uterine tissue dissociated by mincing with sterile scissors for about $1 \mathrm{~min}$ and the mixture incubated at $37^{\circ} \mathrm{C}$ for $30 \mathrm{~min}$. After the second enzyme treatment, heat-inactivated fetal calf serum $(5 \%)$ was added and the cell suspension centrifuged at $500 \mathrm{~g}$ for $20 \mathrm{~min}$, the supernatant discarded and the pellet resuspended in culture medium supplemented with or without steroid hormone where indicated. Cells were plated out into four-well multidishes (Nunc) at $1.3 \times 10^{6}$ cells per well and the dishes placed in a $37^{\circ} \mathrm{C}$ incubator in a humidified atmosphere of $5 \% \mathrm{CO}_{2}$ in air. Cells were cultured for $48 \mathrm{~h}$ in the presence, or absence, of steroid hormones; oestradiol $\left(3.7 \times 10^{-5} \mathrm{~mol} \mathrm{l}^{-1}\right)$, progesterone $\left(3.2 \times 10^{-6} \mathrm{~mol} \mathrm{l}^{-1}\right)$ or both steroid hormones together (Lavranos and Seamark, 1989). The cells were then collected by treatment with $0.05 \%(\mathrm{v} / \mathrm{v})$ trypsin and $0.02 \%$ ( $\mathrm{v} / \mathrm{v})$ EDTA in EBSS, centrifuged at $500 \mathrm{~g}$ for $10 \mathrm{~min}$; the supernatant was aspirated and discarded; and the tubes containing cells stored at $-80^{\circ} \mathrm{C}$ for subsequent extraction of RNA. This experiment was repeated twice. Total RNA from each group of cells was assayed for LIF expression by ribonuclease protection assays.

\section{$R N A$ analyses}

Total RNA was isolated as described by Edwards et al. (1985). Ribonuclease protection assays were carried out essentially as described by Rathjen et al. (1990a). Total RNA ( $5 \mu \mathrm{g})$ was hybridized with probe in the absence of added tRNA. Hybridizations were carried out at $45^{\circ} \mathrm{C}$ for $16-20 \mathrm{~h}$. RNA hybrids were digested with $40 \mu \mathrm{g}$ RNAaseA ml ${ }^{-1}$ (Boehringer Mannheim, Mannheim) and $2 \mu \mathrm{g}$ RNAase $\mathrm{T} 1 \mathrm{ml}^{-1}$ (Bethesda Research Laboratories, Bethesda, MD) at $4^{\circ} \mathrm{C}$ for $30 \mathrm{~min}$. Protected fragments were analysed on a $5 \%$ polyacrylamide$8 \mathrm{~mol}$ urea $\mathrm{l}^{-1}$ gel, which was dried before autoradiography. High specific activity riboprobes for LIF were synthesized by transcription of pDR2 in vitro (Rathjen et al., 1990b) with T7 polymerase (Bresatec, Adelaide) after linearization of the template by digestion with Hindll (Rathjen et al., 1990b). The reaction conditions were as described by Krieg and Melton (1987) with the exception that $250 \mu \mathrm{Ci}\left[\alpha-{ }^{32} \mathrm{P}\right] \mathrm{UTP}(3000 \mathrm{Ci}$ $\mathrm{mmol}^{-1}, 10 \mathrm{mCi} \mathrm{ml}^{-1}$; Bresatec) was used in a $15 \mu$ l reaction volume. When using LIF clone pDR2 (Rathjen et al., 1990b) two RNAase protected fragments are produced. The larger fragment (368 nucleotides) corresponds to the diffusible form of LIF and the shorter fragment (345 nucleotides) to the matrix form of LIF, produced by the use of alternative exons at the $5^{\prime}$ end (Rathjen et al., 1990b).

The concentrations of mouse glyceraldehyde-3-phosphate dehydrogenase (mGAP) mRNA were also determined and used as a control to show that equal amounts of total RNA had been analysed from each sample. The GAP riboprobe was synthesized in a $15 \mu \mathrm{l}$ reaction volume containing $5 \mu \mathrm{Ci}\left[\alpha-{ }^{32} \mathrm{P}\right] \mathrm{UTP}$ $\left(3000 \mathrm{Ci} \mathrm{mmol}^{-1}, 10 \mathrm{mCi} \mathrm{ml}^{-1}\right.$, Bresatec) and $3 \mu \mathrm{l}$ of $1 \mathrm{mmol}$ UTP $1^{-1}$ to reduce overexposure of the GAP signal relative to the LIF signal. This yielded probes of 500 -fold lower specific activity than the LIF probes. The GAP signal consists of a triplet of protected bands at approximately $250 \mathrm{bp}$. An error (orientation of insert) was made in the original description of the preparation of the GAP probe (Nomura et al., 1989). Antisense RNA was generated using SP6 transcription of BamHI-linearized plasmid, and the three protected bands in mouse RNA represent heterogeneity at the $5^{\prime}$ end as reported previously (Rathjen et al., 1990a).

\section{Statistical analyses}

Results of embryo development were generally analysed by chi-squared tests. The data on the area of embryo inner cell mass and trophoblast following culture in vitro with LIF were analysed using Student's $t$ test. 
Table 1. The effect of myeloid leukaemia inhibitory factor (LIF: $1000 \mathrm{U} \mathrm{ml}^{-1}$ ) on the rate of hatching of mouse embryos in vitro

\begin{tabular}{lccccc}
\hline & & \multicolumn{3}{c}{ Percentage hatching $^{2}$} & \\
\cline { 4 - 5 } Treatment & $n$ & $96 \mathrm{~h}$ & $100 \mathrm{~h}$ & $120 \mathrm{~h}$ & $\begin{array}{c}\text { Percentage } \\
\text { hatched }\end{array}$ \\
\hline Control & 66 & 7.6 & 68.9 & 70 & 62.1 \\
LIF & 74 & $33.8^{* * *}$ & $93.2^{* * *}$ & 98.6 & $85.1^{*}$ \\
\hline
\end{tabular}

"Time after hCG injection.

Asterisks indicate significant differences from respective control groups: $* p<0.05 ; * * *<0.001$.

\section{Results}

Effects of LIF on the development of one-cell embryos

When the medium was supplemented with a range of concentrations of LIF $\left(62.5 \mathrm{U} \mathrm{ml}^{-1}\right.$ to $\left.2000 \mathrm{U} \mathrm{ml}^{-1}\right)$ the results obtained (data not shown) did not differ from those obtained for LIF at $1000 \mathrm{U} \mathrm{ml}^{-1}$. The addition of LIF (1000 U $\mathrm{ml}^{-1}$ ) did not significantly alter the proportion of embryos developing from the one-cell stage through to the blastocyst stage, compared with the unsupplemented group $(84.1 \%$ or $58 / 69$ versus $90.1 \%$ or $64 / 71$, respectively). After daily observation and assessment of the rate of growth and development, no significant differences in either the rate of development or the total number of embryos reaching a particular stage of development were evident between the unsupplemented and LIF-supplemented groups throughout the culture period. Thus LIF appeared to have no effect on development of embryos from the one-cell stage.

\section{Effects of LIF on the development of eight-cell embryos}

Robertson et al. (1990) found that culture of eight-cell embryos in medium supplemented with LIF (1000 $\left.\mathrm{U} \mathrm{ml}^{-1}\right)$ for a period of 5 days significantly increased $(P<0.01)$ the total number of embryos exhibiting trophoblast outgrowth in vitro from $64 \%$ (223 of 349 ) to $80 \%$ (156 of 195) of eight-cell embryos cultured in unsupplemented medium. The experiments reported here, using a concentration of LIF of $1000 \mathrm{U}$ $\mathrm{ml}^{-1}$, found that significantly $(P<0.001)$ greater proportions of LIF-treated embryos were hatching $96 \mathrm{~h}$ after hCG treatment $(33.8 \%)$ when compared with the unsupplemented group $(7.6 \%)$, suggesting that LIF had accelerated their rate of development. Furthermore, the total number of LIF-treated embryos that completely hatched $(85.1 \%)$ was significantly $(P<0.05)$ greater than the number observed in the unsupplemented group $(62.1 \%)$ (Table 1). Continued observation and assessment of embryo growth and development revealed that a significant $(P<0.01)$ proportion $(13.5 \%)$ of LIF-treated embryos had attained stage 2 (trophectoderm cells attached to the bottom of the dish) $120 \mathrm{~h}$ after hCG treatment compared with none in the unsupplemented group (Table 2). By $144 \mathrm{~h}$ after hCG treatment, trophoblast outgrowth was complete (stage 3 ) in $85.1 \%$ of LIF-treated embryos compared with only
Table 2. The effect of myeloid leukaemia inhibitory factor (LIF: $1000 \mathrm{U} \mathrm{ml}^{-1}$ ) on the rate of trophoblast outgrowth (stage 2 to stage 3$)^{a}$ of mouse embryos in vitro

\begin{tabular}{lcccc}
\hline & \multicolumn{4}{c}{ Percentage outgrowth } \\
Treatment & $n$ & $120 \mathrm{~h}$ & $144 \mathrm{~h}$ & $168 \mathrm{~h}$ \\
& & & & \\
\hline Control & 66 & 0 & 47.0 & 62.1 \\
LIF & 74 & $13.5^{* *}$ & $85.1^{* *}$ & $85.1^{*}$
\end{tabular}

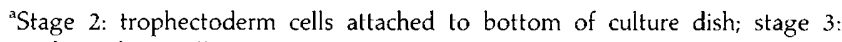
trophectoderm cells spread out on the bottom of culture dish.

${ }^{\mathrm{b}}$ Time after hCG injection.

Asterisks indicate significant differences from respective control groups: $* P<0.05 ; * * P<0.01$.

Table 3. The effect of different culture periods in medium supplemented with myeloid leukaemia inhibitory factor (LIF: $1000 \mathrm{U} \mathrm{ml}^{-1}$ ) on mouse embryo development after the blastocyst stage in vitro

Period of culture with LIF

Percentage $n \quad$ developing to stage $3^{\text {a }}$

None (control)

8 -cell to stage 3

8-cell to blastocyst

Blastocyst to stage 3

$\begin{array}{ll}35 & 54.3 \\ 35 & 77.1 \\ 35 & 65.7 \\ 35 & 85.7^{* *}\end{array}$

${ }^{a}$ Stage 3: trophectoderm cells spread out on the bottom of the culture dish. ** Significantly different from control $(P<0.01)$.

$47 \%$ of the embryos cultured in unsupplemented medium $(P<0.01)$. An additional $24 \mathrm{~h}$ was required by these control embryos for all hatched blastocysts to reach stage 3 (Table 2). Thus LIF clearly advanced the rate of hatching and trophoblast outgrowth of eight-cell embryos in vitro.

\section{Effects of LIF on development after the blastocyst stage}

Eight-cell embryos were cultured in vitro in unsupplemented medium to the blastocyst stage, treated with LIF and analysed for developmental effects to determine the developmental stage at which embryos are responsive to LIF. The addition of $1000 \mathrm{U} \mathrm{LIF} \mathrm{ml}^{-1}$ resulted in a significant $(P<0.01)$ increase in the number of embryos reaching stage 3 (trophoblast outgrowth) compared with embryos cultured continuously in unsupplemented medium $(85.7 \%$ or 30 of 35 versus $54.3 \%$ or 19 of 35). In contrast, addition of LIF to embryos between the eight-cell stage and the blastocyst stage failed to affect subsequent development. Blastocysts were derived from eightcell embryos cultured in the presence or absence of 1000 U LIF $\mathrm{ml}^{-1}$. Continued culture of these embryos in unsupplemented medium revealed no significant difference in the ability of these embryos to reach stage 3 of development $(65.7 \%$ versus $54.3 \%$ ) (Table 3). These results clearly indicate that mouse embryos 

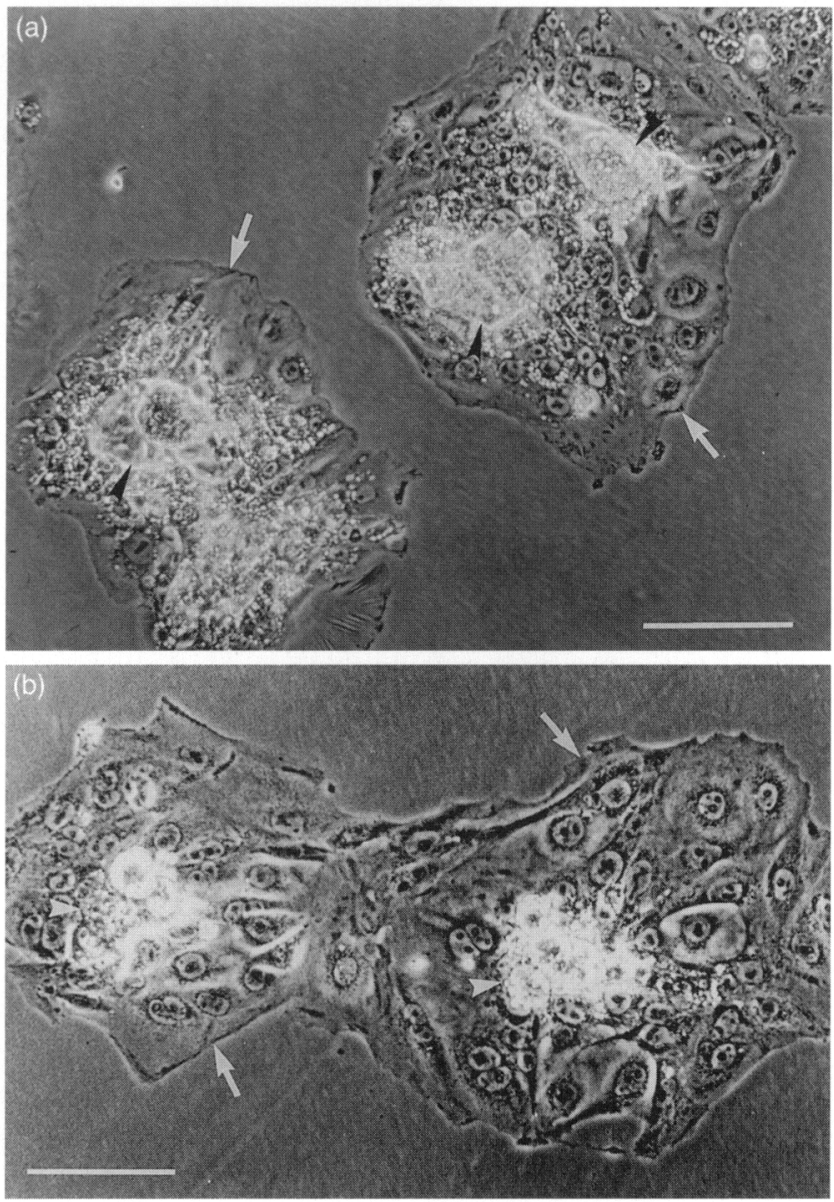

Fig. 1. (a) Four control mouse embryos (unsupplemented medium) and (b) two mouse embryos treated with myeloid leukaemia inhibitory factor cultured for 5 days in vitro. The arrows indicate the expanded trophoblast and the arrowheads indicate an inner cell mass. Scale bars represent $100 \mu \mathrm{m}$.

respond to LIF in vitro only after the eight-cell stage of development.

\section{Effects of LIF on embryo inner cell mass and trophoblast}

Image analyses were performed to measure the area of inner cell mass and the trophoblastic outgrowth of embryos. At day 5 of culture, the mean trophoblastic area of embryos cultured in LIF-supplemented medium (1000 $\mathrm{U} \mathrm{ml}^{-1}$ ) was $27 \%$ greater than controls (111 $\pm 30.7 \mu^{2}$ versus $141 \pm 35.2 \mu \mathrm{m}^{2}$, respectively; $P<0.005)$. There were no significant $(P<0.05)$ differences in the areas of the inner cell mass of embryos cultured in unsupplemented medium $\left(8.0 \pm 3.5 \mu^{2}\right)$ and LIF-treated embryos $\left(8.3 \pm 3.4 \mu \mathrm{m}^{2}\right)$ at this stage of culture (Fig. 1). By day 7 , the mean area of the inner cell mass of LIF-treated embryos $\left(15.9 \pm 10.6 \mathrm{um}^{2}\right)$ was significantly $(P<0.025)$ greater than that of the control embryos $\left(10.3 \pm 5.7 \mu \mathrm{m}^{2}\right)$, and the trophoblastic area was $43 \%$ greater $(P<0.005)$ in LIF-treated embryos $\left(296 \pm 67.2 \mu^{2}\right)$ than in embryos cultured in unsupplemented medium ( $207 \pm 67.8 \mu \mathrm{m}^{2}$ ). Thus LIF-treated embryos exhibit greater trophoblastic spreading as early as day 5 in culture.
Table 4. The effect of treating mouse embryos with myeloid leukaemia inhibitory factor (LIF: $1000 \mathrm{U} \mathrm{ml}^{-1}$ ) during culture in vitro followed by embryo transfer to synchronized pseudopregnant females

Stage of embryo at time of transfer

\begin{tabular}{llllll}
\hline & \multicolumn{2}{c}{ Hatching } & & \multicolumn{2}{c}{ Hatched } \\
\cline { 2 - 3 } \cline { 6 - 6 } Parameter & Control & LIF & & Control & LIF \\
\hline Number transferred & 52 & 52 & & 32 & 32 \\
Percentage implanted & 90.2 & 90.4 & & 84.4 & 81.3 \\
Percentage reabsorbed & 30.0 & 29.8 & & 33.3 & $19.2^{* * *}$ \\
Percentage fetuses & 70.0 & 70.2 & & 66.7 & $80.8^{*}$ \\
& & & & & \\
\hline
\end{tabular}

Asterisks indicate significant differences from respective control groups $* P<0.05 ; * * * P<0.001$.

\section{Embryo viability following treatment with LIF}

Eight-cell embryos were collected, cultured for $48-50 \mathrm{~h}$ with or without LIF and then transferred to the uteri of day 2.5 pseudopregnant recipient mice. Embryos were cultured until they developed to either the hatching stage of development, or until they had completely hatched in vitro. Only embryos from the unsupplemented medium group and the LIF-supplemented group that had attained each of these stages of development were then transferred to pseudopregnant females. On day 15 of gestation, the recipient mice were killed and their reproductive tracts were examined. The LIF-treated group that had been transferred at the hatching blastocyst stage exhibited no significant $(P>0.05)$ differences in development from those of the unsupplemented group (Table 4). However, there were fewer embryos reabsorbed in the LIF-treated group of embryos that were transferred at the hatched stage $(19.2 \%)$ compared with controls $(33.3 \%) \quad(P<0.001)$. Reabsorptions of untreated and LIF-treated embryos were randomly distributed among females. In concord with the fewer reabsorptions, a significant $(P<0.05)$ increase in the number of live fetuses was also observed in the LIF-treated group $\{80.8 \%)$ compared with the unsupplemented group $(66.7 \%)$ (Table 4). Thus, LIF treatment increased the survival of embryos in vivo.

\section{LIF expression in uterine cells in vitro}

Expression of the LIF transcript (diffusible form), which in the ribonuclease protection assay is viewed as a protected band of $368 \mathrm{bp}$, was observed in endometrial cells cultured as monolayers from females at day 3 of pregnancy (Fig. 2). The expression of this transcript at relatively high concentrations is consistent with reports of LIF (diffusible form) expression by the uterus in pregnant and virgin females (Bhatt et al, 1991; Shen and Leder 1991; Robertson et al., 1993). Expression of the transcript was not significantly affected by treatment of the cells with progesterone $(3.2 \times$ $\left.10^{-6} \mathrm{~mol} \mathrm{l}^{-1}\right)$ or oestradiol $\left(3.7 \times 10^{-5} \mathrm{~mol} \mathrm{l}^{-1}\right)$ alone or in combination. 


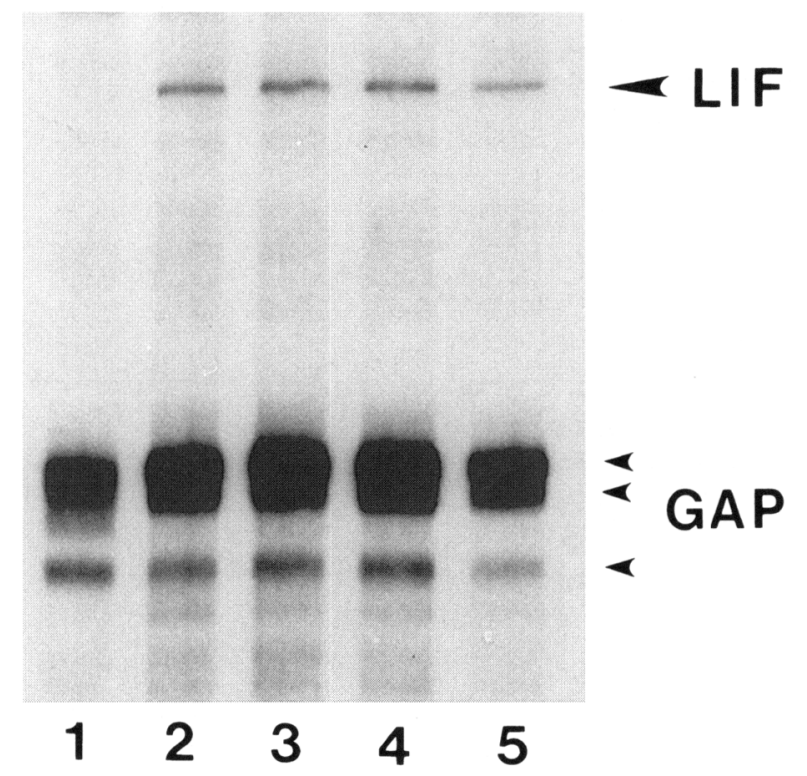

Fig. 2. Expression of transcripts of myeloid leukaemia inhibitory factor (LIF) by uterine monolayers in vitro. RNAse protection analysis of LIF transcripts (large arrow) was carried out as reported previously (Rathjen et al., 1990a) using $5 \mu \mathrm{g}$ total RNA isolated from: (lane I) embryonic stem cells; endometrial cells from day 3 pregnant mouse uteri following culture with (lane 2) oestradiol $\left(3.7 \times 10^{-5} \mathrm{~mol} \mathrm{l}^{-1}\right)$ and progesterone $\left(3.2 \times 10^{-6} \mathrm{~mol} 1^{-1}\right)$, (lane 3) oestradiol $(3.7 \times$ $\left.10^{-5} \mathrm{~mol} \mathrm{l} \mathrm{l}^{-1}\right)$ alone, (lane 4) progesterone $\left(3.2 \times 10^{-6} \mathrm{~mol} \mathrm{l}-1\right.$ ) alone and (lane 5) without steroid hormones. Mouse glyceraldehyde3-phosphate dehydrogenase (GAP) (small arrows) was used as a loading control. One representative experiment of two performed.

\section{Discussion}

In the present work, exogenous soluble LIF was shown to enhance the development of early mouse embryos in vitro. Treatment of embryos with LIF resulted in accelerated hatching, increased survival, increased proliferation of trophoblast cells and growth of the inner cell mass. Embryonic survival and progression in vivo, as evidenced by the transfer of embryos to pseudopregnant mice, was also enhanced by LIF treatment of embryos in vitro.

The action of LIF in promoting embryonic development was most effective at about the time of blastocyst formation. Treatment of embryos with LIF at earlier developmental stages, such as at the one-eight cell stage, when in vivo the embryo is located within the oviduct, had no measurable effect on embryogenesis in vitro. This lack of effect of LIF on embryos at the one-eight cell stage is interesting, given that the mouse oviduct is known to express LIF (Bhatt et al., 1991; Shen and Leder, 1992) and it might be expected that the embryo at this stage would be bathed in LIF. The blastocyst stage of development in mice is followed by implantation of the embryo. At this stage there is a surge of LIF expression in the maternal endometrial glands and this appears to be necessary for blastocyst implantation (Stewart et al., 1992). The principal effect of LIF on embryo development in vitro therefore coincides with the time at which maternal expression of the factor is expected to be highest.
The stimulatory effects of LIF on embryogenesis were manifest in greater inner cell mass and increased trophectoderm proliferation. This increase in inner cell mass and trophectoderm could represent a direct effect of LIF on these cells, given that LIF receptors have been identified on cells of the trophectoderm (Fry, 1992) and on embryonic stem cells (Williams et al., 1988) which are analogous to the cells of the inner cell mass. Biological actions of LIF on trophectoderm cells have not been described. LIF prevents the differentiation of embryonic stem cells in vivo (Smith et al., 1988; Williams et al., 1988), which in an embryonic context could result in increased proliferation of the inner cell mass. However, it is not known whether exogenous LIF can gain access to cells of the inner cell mass in vitro, although translocation of LIF across polar trophectoderm in a manner analogous to that described for insulin (Heyner et al., 1989) cannot be excluded. It is possible that all cells of the early embryo could be in contact with LIF in vivo, which is expressed at a variety of sites including the uterine lining and the extraembryonic portion of the conceptus. Although the embryotrophic effects of LIF could result from direct action on the inner cell mass and trophectoderm cell populations, the possibility of secondary or paracrine interactions, initiated by exogenous LIF and resulting in embryotrophic effects, cannot be excluded.

Maternal expression of LIF in the uterus appears to be stimulated, directly or indirectly, by progesterone and oestradiol. These hormones enhance embryonic development in mice in vitro but only when early embryos are cultured in the presence of uterine monolayers; an effect which could be explained if the action of the hormones was indirect, perhaps via an embryotrophic factor produced by the uterine monolayer. LIF is a good candidate for such a factor given its known expression pattern in vivo and the embryotrophic effects reported here. Consistent with the known expression of LIF in the female reproductive tract, strong expression of the LIF (diffusible form) transcript by uterine monolayers in vitro was observed, suggesting the production of diffusible LIF. However, this LIF expression was not noticeably increased by the addition of progesterone and oestradiol, alone or in combination. The failure to observe a steroid-mediated increase of LIF transcription in these cells could reflect a requirement for an intermediate factor not present in this system, or possibly that LIF transcription can be greatly increased in vivo by factors often present in serum (Rathjen et al., 1990a).

The observation that uterine monolayers express LIF transcripts in vitro and that LIF can have an embryotrophic effect on early development provide an explanation for the previously reported stimulatory effects of uterine monolayers on early development in mice in vitro (Lavranos and Seamark, 1989). This earlier study on endometrial cell and embryo coculture showed no enhancement of embryo development when eightcell embryos were cultured with steroid hormones alone or with uterine cells alone. The enhancement of embryonic growth and development by steroid hormones was seen only in coculture. The enhanced embryotrophic effect induced in this coculture system by steroid hormones would, however, need to be explained by an alternative hypothesis, since treatment of the uterine monolayers with steroid hormones did not alter LIF expression. The positive effects of steroid hormones on embryogenesis in mice in the presence of uterine monolayers 
must therefore be distinct from the embryotrophic effects of exogenous LIF reported in this paper. This implicates the secretion of other embryotrophic factors by uterine monolayers in response to steroid hormones, or the reorganization of the uterine epithelium to provide the embryo with an improved environmental matrix. In this regard it is interesting that other cytokines and growth factors, including CSF-1 (Arceci $e$ al., 1989), can be produced by the uterine epithelium. The relationship between the LIF-mediated and steroidmediated effects on embryogenesis in vitro, and the known requirement for LIF for implantation in vivo, cannot be assessed on the basis of the data presented here.

The data presented in this paper, in combination with previous reports, indicate that LIF may have a dual role in early development in mice. Maternal LIF production is necessary for embryo implantation. It is possible that LIF may have a secondary role, as an embryotrophic factor. Data obtained from gene inactivation in mice indicate that there is no absolute requirement for embryonic LIF expression for the development of the embryo, although the observation that LIF-deficient embryos are smaller than heterozygous littermates (Stewart et al., 1992) is interesting given our identification of the embryotrophic activity of LIF. Maternal LIF expression is not required for development of the embryo to the blastocyst stage, since viable blastocysts can be recovered from LiFdeficient mothers (Stewart et al., 1992). Potential embryotrophic effects of maternal LIF expression beyond this point of embryogenesis cannot be easily assessed by gene inactivation strategies which result in the absence of embryo implantation. This is unfortunate given that our results indicate that the main embryotrophic effects of LIF follow formation of the blastocyst, and possibly implantation.

Interactions between mother and fetus during early embryogenesis are complex but critical for regulated construction of the embryonic environment. The importance of maternal LIF expression in this process has been established by mutational analyses. We have now demonstrated a potential second role for LIF in early embryogenesis, as an embryotrophin. Our suggestion that there may be multiple roles for LIF at this stage of development is compatible with the multiple embryonic and extraembryonic expression sites, and indicates the complexity of the regulatory network governing maternal-fetal interactions.

The authors would like to thank AMRAD Corp. Limited, Melbourne for their generous gift of recombinant LIF, and to thank P. Verma for his assistance in the uterine transfer experiments. This study was financially supported by a grant from the Swine Compensation Fund of South Australia.

\section{References}

Arceci RJ, Shanahan F, Stanley ER and Pollard JW (1989) Temporal expression and location of colony-stimulating factor 1 (CSF-1) and its receptor in the female reproductive tract are consistent with CSF-1-regulated placental development Proceedings of the National Academy Sciences USA 868818 8822

Bhatt H, Brunet LJ and Stewart CL (1991) Uterine expression of leukemia inhibitory factor (LIF) coincides with the onset of blastocyst implantation Proceedings of the National Academy of Sciences USA 8811 40811412
Brigstock DR, Heap RB and Brown KD (1989) Polypeptide growth factors in uterine tissues and secretions Journal of Reproduction and Fertility 85 747-758 Conquet $\mathbf{F}$ and Brùlet $\mathbf{P}$ (1990) Developmental expression of myeloid leukemia inhibitory factor gene in preimplantation blastocysts and in extraembryonic tissue of mouse embryos. Molecular and Cellular Biology 10 380I-3805

Conquet F, Peyriéras N, Tiret L and Brûlet P (1992) Inhibited gastrulation in mouse embryos overexpressing the leukemia inhibitory factor Proceedings of the National Academy of Sciences USA 89 8195-8199

Edwards DR, Parfett CL and Denhardt DT (1985) Transcriptional regulation of two serum-induced RNAs in mouse fibroblasts Molecular and Cellular Biology 5 3280-3288

Fry RC (1992) The effect of leukemia inhibitory factor (LIF) on embryogenesis Reproduction Fertility and Development 4 449-458

Gough NM, Williams RL, Hilton DJ, Pease S, Willson TA, Stahl J, Gearing DP, Nicola NA and Metcalf D (1989) LIF; a molecule with divergent actions on myeloid leukaemic cells and embryonic stem cells Reproduction Fertility and Development $1281-288$

Heyner S, Rao LV, Jaratt L and Smith RM (1989) Preimplantation mouse embryos internalize maternal insulin via receptor-mediated endocytosis: pattern of uptake and functional correlations Developmental Biology 134 $48-58$

Hill DJ, Strain AJ and Milner RDG (1987) Growth factors in embryogenesis. In Oxford Reviews in Reproduclive Biology Vol. 9 pp 398-455 Ed. JR Clarke. Oxford University Press, New York

Hilton DJ, Nicola NA and Metcalf D (1988) Specific binding of murine leukemia inhibitory factor to normal and leukemic monocytic cells Proceedings of the National Academy of Sciences USA 85 5971-5975

Hogan B, Costantini F and Lacy E (1986) Embryo transfers. In Manipulating the Mouse Embryo. A Laboratory Manual pp 142-145 Cold Spring Harbor Laboratory Press, New York

Hsu Y-C (1979) in vitro development of individually cultured whole mouse embryos from blastocyst to early somite stage Developmental Biology 68 453-461

Krieg PA and Melton DA (1987) In vitro RNA synthesis with SP6 RNA polymerase Methods in Enzymology 155 397-415

Lavranos TC and Seamark RF (1989) Addition of steroids to embryo-uterine monolayer co-culture enhances embryo survival and implantation in vitro Reproduction Fertility and Development 1 41-46

Metcalf D (1989) Actions and interactions of G-CSF, LIF and IL-6 on normal and leukemic murine cells Leukemia 3 349-355

Moreau J-F, Donaldson DD, Bennett F, Witek-Giannotti J, Clark SC and Wong GG (1988) Leukaemia inhibitory factor is identical to the myeloid growth factor human interleukin for DA cells Nature 336 690-692

Nomura S, Hogan BL, Wills AJ, Heath JK and Edwards DR (1989) Developmental expression of tissue inhibitor of metalloproteinase (TIMP) RNA Development $105575-583$

Pollard JW (1990) Regulation of polypeptide growth factor synthesis and growth factor-related gene expression in the rat and mouse uterus before and after implantation Journal of Reproduction and Fertility 88 721-731.

Pollard JW, Bartocci A, Arceci R, Orlofsky A, Ladner MB and Stanley ER (1987) Apparent role of the macrophage growth factor, CSF-I, in placental development Nature $330484-486$

Quinn P, Kerin JF and Warnes GM (1985) Improved pregnancy rate in human in vitro fertilization with the use of medium based on the composition of human tubal fluid Fertility and Sterility 44 493-498

Rathjen PD, Nichols J, Toth S, Edwards DR, Heath JK and Smith AG (1990a) Developmentally programmed induction of differentiation inhibiting activity and the control of stem cell populations Genes and Development 4 2308-2318

Rathjen PD, Toth S, Willis A, Heath JK and Smith AG (1990b) Differentiation inhibiting activity is produced in matrix-associated and diffusible forms that are generated by alternate promoter usage Cell 62 1105-1114

Robertson M, Chambers I, Rathjen P, Nichols J and Smith A (1993) Expression of alternative forms of differentiation inhibiting activity (DIA/LIF) during murine embryogenesis and in neonatal and adult tissues Developmental Genetics 14 165-173

Robertson SA, Lavranos TC and Seamark RF (1990) In vitro models of the maternal fetal interface. In The Molecular and Cellular Immunobiology of the Maternal-Fetal Interface pp 191-206 Eds TG Wegmann, E Nisbett-Brown and TJ Gill, 11l. Oxford University Press Inc., New York

Salomon DS and Sherman MI (1975) Implantation and invasiveness of mouse blastocysts on uterine monolayers Experimental Cell Research 90 261-268 
Shen MM and Leder P (1992) Leukemia inhibitory factor is expressed by the preimplantation uterus and selectively blocks primitive ectoderm formation in vitro Proceedings of the National Academy of Sciences USA 89 8240-8244

Sherman MI (1978) Implantation of mouse blastocysts in vitro. In Methods in Mammaliant Reproduction pp 81-125 Ed. JC Daniel, Jr. Academic Press, New York

Smith AG, Heath JK, Donaldson DD, Wong GG, Moreau J, Stahl M and Rogers D (1988) Inhibition of pluripotential embryonic stem cell differentiation by purified polypeptides Nature $336688-690$

Stewart CL, Kaspar P, Brunet LJ, Bhatt H, Gadi I, Kontgen F and Abbondanzo SJ (1992) Blastocyst implantation depends on maternal expression of leukaemia inhibitory factor Nature $\mathbf{3 5 9} 76-79$
Wegmann TG (1988) Maternal T cells promote placental growth and prevent spontaneous abortion Immunology Letters 17 297-302

Wegmann TG, Athanassakis I, Guilbert L, Branch D, Dy M, Menu E and Chaouat G (1989) The role of M-CSF and GM-CSF in fostering placental growth, fetal growth, and fetal survival Transplant Proceedings 21 566-568

Williams RL, Hilton DJ, Pease S, Willson TA, Stewart CL, Gearing DP, Wagner EF, Metcalf D, Nicola NA and Gough NM (1988) Myeloid leukaemia inhibitory factor maintains the developmental potential of embryonic stem cells Nature $336684-687$

Yamamori T, Fukada K, Aebersold R, Korsching S, Fann M-J and Patterson PH (1989) The cholinergic neuronal differentiation factor from heart cells is identical to leukemia inhibitory factor Science 246 1412-1416 